\title{
Research on Innovative Design of Portable Quick-drying Machine
}

\author{
Shi Yao-jun*, Wu Nai-qun and Dai Ye \\ School of Mechanical \& Power Engineering, Harbin University of Science and \\ Technology, Heilongjiang Harbin 150080, China \\ wwwsyj@sina.com
}

\begin{abstract}
As science continues to progress, human civilization has ever enter into a new realm. Household electrification has become a symbol of progress. In southern China and some humid regions in foreign countries, clothes are still wet in several days after washing. People deeply suffered from it. The invention of clothing quick-drying device has solved this problem and has brought great convenience to people living in wet areas. According to the need of the people at home or traveling, this paper brought a new design conception which makes innovative design and research from the function and structure, materials and technology and human relationships. To let people use it at the same time feel a happy convenience life.
\end{abstract}

Keywords: portable; clothes; quick-drying; design

\section{Introduction}

Clothes quick-drying device is also known as clothes-dryer which uses electric to dry laundry automatically. It is a space-saved environment-friendly and multifunctional machine which solves the problem of drying clothes in raining days especially in southern humid area or no space to hang clothes. With the continuous improvement of people's living standards in China, the need of clothes quick-drying device has been brought out just like the need of any other home appliances and industrial devices. More clothes dryers on the market are drum-type, non-portable and similar to washing machines. It is difficult to remove and store. Secondly, because the clothes are rotated in the drum caused by the belt, it is easy to make wrinkles which make clothes unbeautiful to wear. Based on the above reasons, we need a clothes dryer which is able to be accepted by the masses, convenient and portable.

The recent portable clothes-dryers are alway household which are big in volume, out of fashion and inconvenient. It is not fit for people who travels a lot. To make the device acceptable and worth to use, the key point is its appearance design and portability. In order to fulfill its portability and its value, the device's function should embodies its market value.

The innovation designs of portable clothes drying device are the following aspect.

\section{Function and Structure}

\subsection{Function}

The function of the device is to use the recycled-heated- wind produced by PTC heating and sent by DC fan controlled by micro-computer smart chip to the dryer cover to discharge the water in the wet clothes. It is quick-completed, friction-free to prevent clothes from broken. The drying process is isolated from the outer environment to prevent from pollution. It works vertically which can keep the clothes from wrinkles[1]. 
The main parameters of PTC elements in the electric-heated appliances as shown in Table 1.

Table 1. Properties of PTC R25

\begin{tabular}{c|c|c|c|c|c}
\hline Resistance & Voltage & Value range & $\begin{array}{c}\text { Anti tolerance } \\
\text { voltage }\end{array}$ & Power & Characteristic \\
\hline$R 25$ & $120-125 \mathrm{~V}$ & $100 \Omega-10 K \Omega$ & Good & Small & $\begin{array}{c}\text { Small at the } \\
\text { beginning }\end{array}$ \\
\hline$R 25$ & $6-24 \mathrm{~V}$ & $0.5 \Omega-5 \Omega$ & Bad & Big & Big at the beginning \\
\hline
\end{tabular}

(1) Normal temperature resistance is R25.Voltage:120-125V. R25 generally takes $100 \Omega-10 \mathrm{~K} \Omega$;

(2) Curie temperature Tc should be moderate. Under certain conditions, the improvement of the Tc could increase electric power consumption of the product correspondingly;

(3) Resistance temperature coefficient should be big, normally at $\geqslant 14$;

(4) Flat appearance, thickness tolerance shall be strictly controlled in $\pm 0.2 \mathrm{~mm}[2]$.

\subsection{Structure}

The main point of design is structure design, the appearance can be thinner and fashioner only by a reasonable structure design. The structure design is not only the reflect of the design of different part of the device but also the key to fulfill the device's function [3].

Line type design, make the shell more tough-feeling and modern. The connected line is designed in small chamfer to avoid the sharp edge. The shell before and after surface is designed in micro bevel [4]. The design is adjusted through the user's perspective and ergonomics perspective to solve the problem of angle between device and wall caused by hanging. Around the groove designed as shown in Figure 1, cleverly solved the problem of containing the wire.

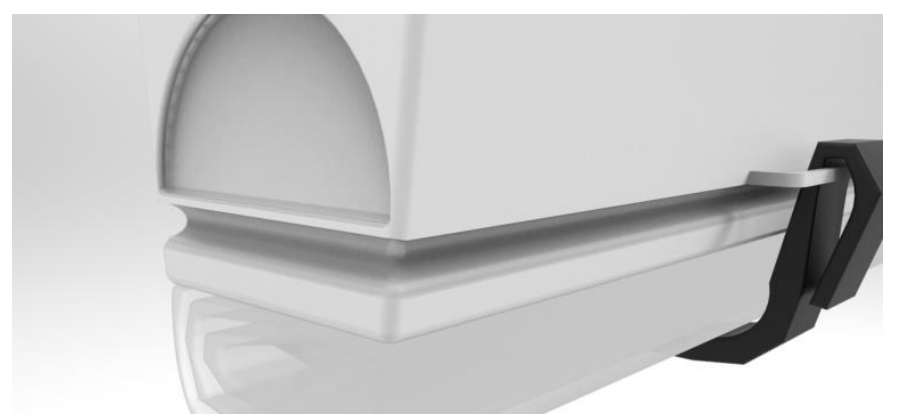

Figure 1. Structure of Containing Wire

The hook of the device which the strength fits for the standard is designed to disassemble and extractable to save some space. As shown in Figure 2. 


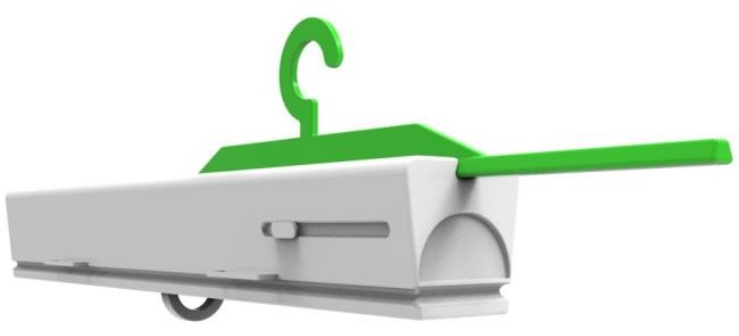

Figure 2. Structure of Hook Device

\section{Material and Technology}

\subsection{Material}

According to the relationship of industry product outlook and material and with the consideration of its structure characteristics,performance,material's property and price, the device uses the following material for each part [5].

1.To use ABS plastic as the main body of the device.

ABS plastic. Chemical name: acrylonitrile butadiene styrene copolymer (Acrylonitrile Butadiene Styrene). ABS plastic resin production is the largest, the most widely used polymer, it combines various properties of PB, PAN and PS together organically and it is tough, hard and with excellent mechanical properties of rigid phase equilibrium. ABS is the three copolymer of acrylonitrile, butadiene and styrene. A stands for acrylonitrile, B stands for butadiene and $S$ stands for styrene. It is found through actual use that ABS plastic pipe is non-resistance to acid and is comminuted fracture with sulphuric acid [6].

Plastic ABS is non-toxic, tasteless and the appearance is ivory white translucent or transparent granule or powder [4].

(1) Mechanical properties

Plastic ABS is with excellent mechanical properties and impact strength. It can be used at very low temperatures; plastics ABS is with excellent wear resistance, good dimensional stability and oil resistance. It can be used for bearing with medium load and low speed. ABS's creep resistance is bigger than PSF and PC, but smaller than $\mathrm{PA}$ and POM.

(2) Thermal properties

ABS plastic's thermal deformation temperature is between $93 \sim 118{ }^{\circ} \mathrm{C}$, ABS product's thermal deformation temperature will increased by $10{ }^{\circ} \mathrm{C}$ after annealing treatment. ABS can still show some resilience at $-40{ }^{\circ} \mathrm{C}$, so it can be used in temperature of $-40 \sim 100^{\circ} \mathrm{C}$.

(3) Electrical properties

Plastic ABS's electrical insulation is good and it is almost not affected by temperature, humidity and frequency. It can be used in most environments [7].

(4) Environmental properties

ABS is not affected by water, inorganic salt, alkali and acid, but it is soluble in ketones, aldehydes and chlorinated hydrocarbon. It could crack by glacial acetic acid, vegetable oil and other erosion ABS's tolerance is poor, it is easy to degradation under the influence of ultraviolet light; its impact strength will decrease a half after half an year in outdoor. The technical parameters of ABS Plastic is shown as Table 2 [8]. 
Table 2. Technical Parameters of ABS Plastic

\begin{tabular}{c|c|c|c|c|c|c|c}
\hline $\begin{array}{c}\text { Density } \\
\left.\mathrm{g} / \mathrm{cm}^{3}\right)\end{array}$ & $\begin{array}{c}\text { Proportion } \\
\left(\mathrm{N} / \mathrm{cm}^{3}\right)\end{array}$ & $\begin{array}{c}\text { Melting } \\
\text { point } \\
\left.{ }^{\circ} \mathrm{C}\right)\end{array}$ & $\begin{array}{c}\text { Decomposition } \\
\text { temperature }\left({ }^{\circ} \mathrm{C}\right. \\
)\end{array}$ & $\begin{array}{c}\text { Forming } \\
\text { shrinkage } \\
\text { rate }\end{array}$ & $\begin{array}{c}\text { Forming } \\
\text { temperature } \\
\left({ }^{\circ} \mathrm{C}\right)\end{array}$ & $\begin{array}{c}\text { Drying } \\
\text { temperature } \\
\left({ }^{\circ} \mathrm{C}\right)\end{array}$ & $\begin{array}{c}\text { Drying } \\
\text { time } \\
(\mathrm{H})\end{array}$ \\
\hline 1.10 & 1.05 & 170 & 260 & 119 & $200-240$ & $80-90$ & 2 \\
\hline
\end{tabular}

ABS plastic's characteristics:

(1) Good comprehensive performance, high impact strength, chemical stability and good electrical properties;

(2) The weldability with 372 organic glass is good and easy to be made of double color plastic parts. It could be chrome plated and spray paint processed;

(3) High impact resistance, high heat resistance, and the level of flame retardant, enhancement and transparency is good;

(4) The liquidity ratio is less than HIPS, PMMA, PC, and with good flexibility;

(5) It is suitable for making general parts, wear resistant parts, transmission parts and electrical parts [9].

\section{Use OXFORD weave as cover}

Oxford weave is a kind of new material which is diverse in function and widely used. The set of lattice, elastic, Teague and other varieties are commonly found in the current market. This product material is teague tissue texture which is woven on spraying loom, the organize is polyester DTY400D yarn and the tram is polyester DTY thread 400D. Fabric design is novel with unique technology. The check pattern on positive side is highlighting, strong sense of three-dimensional and the most prominent part of fabric, while the negative side is dealt with coating (PU) technology to make it waterproof and with better drapability. The material's texture is light, soft-hand-feeling, waterproof and durable. Fabric width is $160 \mathrm{~cm}$. Now black, navy blue, Coffee are the main color on the market [10].

3. The inside of the heater adopts the semiconductor composed of PTC

PTC is a positive temperature coefficient thermistor material, has the characteristics of resistivity with temperature increasing. Major breakthroughs have been made in the study of continuous research of PTC material. PTC material theory has become more mature and its application scope is expanding. A lot of new PTC materials also appeared in recent years, such as organic compound PTC etc., [11]. PTC material is shown as Figure 3.

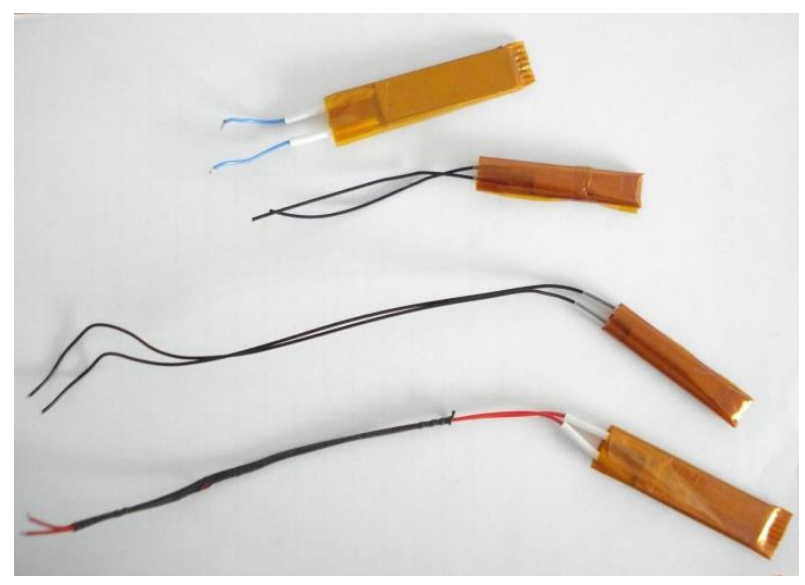

Figure 3. PTC Material 


\subsection{Technology}

The inner surface design is easy in contrast. Its molding technology is shown as Figure 4. The first step of mold is to put granular or powdery raw material into the hooper of injection machine. Raw material melt into flow state after heating and injected into the mold cavity through nozzle and injection system under the action of the piston, to been hardening shaping in the cavity [12].

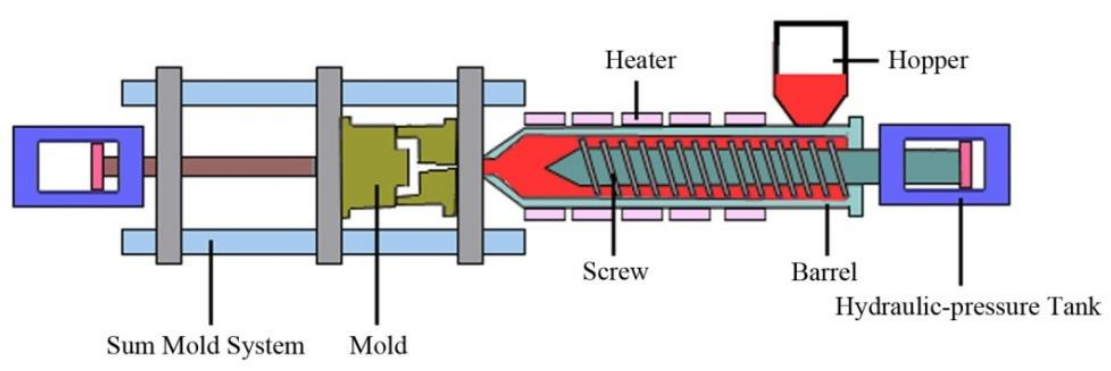

Figure 4. Injection Molding

The selection of parting surface is a key in injection molding. It is an important factor to decide the mold structure and relates to the overall structure of mold, pouring system design, plastic parts ejection and die manufacturing process. The parting surface should be at the maximum contour shape of plastic parts, should be easy to de-mold smoothly. It also should ensure the dimensional accuracy and surface quality of plastic parts and is helpful to mold processing and exhaust.

In the process of top rack design, injection mold should only has one parting surface. The shape of the parting surface is flat and at the maximum profile of the plastic parts . The plastic parts should be on the moving die side after molding which is easy for the plastic parts to eject. The choice of parting has guarantee the dimensional accuracy and surface quality of plastic parts. It is also conducive to mold processing, exhaust and meets the design principles. The hanger part requires a weather resistance and excellent collective stability, which requires materials to be with high strength and homogeneity [13].

\section{Man-machine Relationship}

Ergonomics is a young science who is the application of physiology, psychology and medical science knowledge, It study the relationship between the human-machine system of man and machine, to improve the emerging interdisciplinary science. The whole system is efficiency. With the high development of mechanization, automation and computerization, human factors in the production of more and more important. So we must think about the Man-machine relationship in design.

Since it has the characteristics of easy to carry, portable products have special requirements in product design. Portability is both to the embodiment of the product function and personality to meet the demand of users. Users put forward higher demands for unlimited use of products. Along with modern industrial design theory gradually penetrated into the actual product development, portable products with novel appearance, beautiful, the characteristics of small volume and easy to carry, have greatly enriched the modern function of the product and the applicable scope [14].

In portable products, the size is a basic element, it should always follow the head principle of mobility to determine the size of the product. The human body size and body movements scale is the basis for determining a portable product size, also is the basis for portable design. 
(1) Two kinds of circumstances to investigate the size of portable product elements. The first case is the size of small handheld portable product design. For small handheld portable product, due to the use of modern high-tech and a variety of high integration of the components applied to the product, the size of the product itself is small enough ,to blindly go to shrink the volume of a product is no longer important to the influence of portability, therefore, the size of portable product should under the way of use in design, to meet the requirements of Man-Machine engineering. The second case is the size of portable hand-held product design. In portable hand-held product design, when determining the roughly size of products, it should based on the basic measure of human body, at the same time should also including different gender and body height, and the determination of its size according to the using of the portable products and the specific way of the hand [15].

(2) The weight of the portable products is a particularly important factor in the design of portable products. The lighter weight of portable products, is not only beneficial to the product of carry, but also conducive to the use of products. The maximum weight parameters for adults handheld products: When take product by the arm from the bad side of position to the appropriate location of the appropriate weight must not exceed $2.3 \mathrm{~kg}$. If overweight, forearm muscles and the shoulder will be easy to fatigue and injury; handheld tools which demand precise point its weight shall not be more than $0.4 \mathrm{~kg}$.

(3) Portable product form is different from the general form of the object, the purpose of existence of portable products are not only for people to use, but also can be convenient to carry, and guarantee users in the process of carrying the product and in normal operation .So it must be rely on playing on a functioning and conform to the requirements of the people actually carrying, etc. The molding of art form is free, portable product design is not simply to form innovation, because it will make portability blur, the result is only superficial, and cannot reflect a portable products function well [16].

Portable clothing drying device design include the ergonomics design, fashion and elegant appearance design, line is dynamic, satisfy the people's aesthetic requirements, shell design conforms to the user's use, hold up to accord with human body palm radian, very comfortable. Grasping position and the matching of a man's hand is palm and fingers to grasp. So you need to conform to the grasping hand tools and Man-Machine relationship.

Man-machine relationship mainly include the diameter, length, etc. By hand muscle structure, can be seen as shown in Figure 5. Because of few palm muscles distribution, and distribution of blood vessels and nerves is intensive, so in a larger power operation, you should to avoid the palm of a lot of pressure, prevent blood in ulnar artery in circulation, causing ischemia, lead to numbness, tingling, etc. At the same time you should focus on the direction and vibration direction not focus on the palm and finger, if the palm pressure vibration for a long time, may be spasm forever. At least easy be fatigue, there is a little space between the operator palms and holding items to reduce the pressure and the effect of friction force [17].

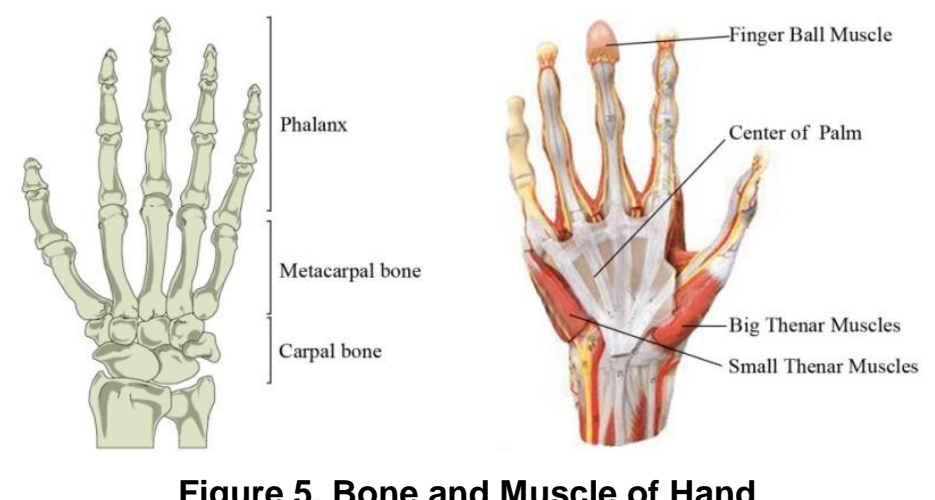

Figure 5. Bone and Muscle of Hand 
After the research of the product in Function ,Material and Man-machine relationship. To make the model with Solidworks software 3D file and render by Keyshot software, The final result as shown in Figure 6.

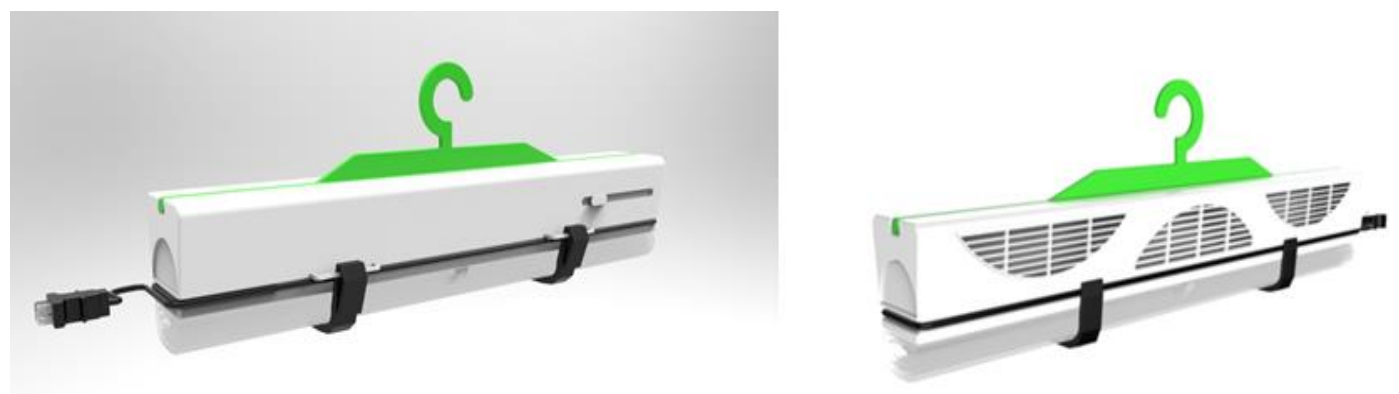

Figure 6. Final Result Picture of Product

\section{Conclusion}

Portable clothing drying device design focus mainly on the innovation for features of the product, molding and portability. To design a new type of drying clothes, provides a reasonable product for the People's daily life and travel. Design brings convenience for the life and happiness when using it at the same time. In this design, not only to solve the selection of materials, components, and the processing technology and some other technical problems, at the same time also need to solve the product appearance, color matching, ergonomics principle of industrial design disciplines etc. By the above research work, the portable clothes drying device can provide users with a whole new way of life and tourism.

\section{Acknowledgement}

The research is supported by Natural Science Foundation of Heilongjiang Province of China (Grant No. E201440) and Heilongiang Province Education Bureau Project (Grant No. 12541146).

\section{References}

[1] Y. J. Wu, "Industrial product form design", Beijing: Beijing institute of technology press, (2006).

[2] X. M. Yu and L. W. Zhong, "Numerical Simulation of Vibration Performance For Nuclear Island Radioactive Boron Acid Water Control Valve", International Conference on Mechanic Automation and Control Engineering, (2010), pp. 3986-3989.

[3] Y. L. Ding, "Ergonomics", Beijing: Beijing institute of technology press, (2002).

[4] Y. L. Perry, "Using steady flow force for unstable valve design: modeling and experiments", Department of Mechanical Engineering, no. 27, (2005), pp. 39-42.

[5] Z. Q. Jian, "Industrial design methodology", Beijing: Beijing institute of technology press, (2010).

[6] X. Li, "Wheel hub design of localization", Packaging Engineering, (2008), vol. 12.

[7] R. Amirante, G. D. Vescovo and A. L. Ippolis, "A flow forces analysis of an open center hydraulic directional control valve sliding spool", Energy Convers Manage, vol. 47, (2006), pp. 114 -131.

[8] G. C. Ren, Y. L. Cui and J. S. Yang, "Industrial product design based Rhino 3D", Packaging Engineering, vol. 1, (2008).

[9] L. Chen, Y. Li, W. Q. Li, "Development of a computer-aided product innovation and design systemCAIP", Computer Integrated Manufacturing Systems, vol. 19, no. 2, (2013), pp. 319-329.

[10] X. R. Zhang, "Industrial design concepts and methods", Beijing: Beijing institute of technology press, (2010).

[11] P. Ren, "Computer-aided industrial design", Beijing: China light industry press, (2001), pp. 2-46.

[12] Y. Dai, Y. Lai and X. B. He, "Design and implementation of MDO integrated system for valve products", Advanced Materials Research, vol. 308, (2011), pp. 1273-1276.

[13] H. Chen, R. Zheng, "Ways to Design 3D Model by Rhino", Computer Knowledge and Technology (Academic Exchange), vol. 35, (2005)

[14] Baiyufan, "Research of the System of Preparing and Exchanging Data of Body Measure for Electronic Made to Measure", Donghua University, (2006). 
International Journal of Control and Automation

Vol. 8, No. 1 (2015)

[15] A. Y.Shi, "Design Foundation Course-Educational Exploration of Man-Machine Engineering", Art and Design, vol. 7, (2008).

[16] Y. Q. Gao, “A Tiredness Model of Monotone Operation Based on Ergonomics”, Mechanical Management and Development, vol. 81, (2007).

[17] L. Y. Feng, X. Y. Min and Z. X. Hui, "The Human-machine Interface Design of the Electronic Instrument Based on Ergonomics", Packaging Engineering, vol. 6, (2011). 